\title{
Impact of COVID-19 on Pediatric and Adult Orthopaedics
}

\author{
Daniel S Hayes, BS ${ }^{1 *}$, S Elliott Holbert, BS², J Alexander Holbert, $M D^{1}$, Mark A Seeley, MD ${ }^{1}$ and Michael \\ Suk, MD, FACS
}

${ }^{1}$ Geisinger Health System, Danville, USA

${ }^{2}$ Edward Via College of Osteopathic Medicine, Blacksburg, USA

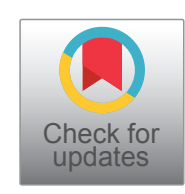

\begin{abstract}
Background: Social practices, hospital guidelines, and government regulations in response to COVID-19 have influenced orthopaedic practice volumes. The widespread cessation of non-essential surgeries has greatly decreased elective practices, but the extent to which trauma volumes diminish remains unknown. Access to common sites of orthopaedic injury were limited during this period, including organized sports, play grounds, and travel.

Methods: To examine the effect of COVID-19 in pediatric and adult practices, considering local responses to the pandemic, weather effects, and school activity. We retrospectively examined orthopaedic clinic changes for the first five months of the year in 2019 and 2020. An administrative data base was used to obtain volume data for OR cases, OP visits, and OP clinic procedures. Temperature and precipitation records were collected for the same period.

Results: All aspects of the adult practice greatly decreased in March, April, and May compared to the previous year. The largest decreases in OR cases occurred in April for adults, with a slight increase in May, but volumes remained decreased compared to the previous year. Pediatric and adult OP visits and OR cases dropped similarly in March and April. This trend continued into May for OP visits, but only pediatric OR visits increased in May.

Conclusions: Practice trends from 2019 to 2020 established in January and February abruptly altered in the following months. Institutional cessation of elective procedures and government issued statewide stay-at-home orders greatly impacted orthopaedic volumes during this period. Decreased opportunity for social activity contributed to drops in pediatric and adult trauma. Proactive responses by local schools aided in a more rapid decline of pediatric trauma compared to adults in the month of March.
\end{abstract}

\section{Keywords}

COVID-19, Pediatric, Trauma, Sports medicine, Orthopaedic, Elective surgery

\section{Background}

The coronavirus SARS-CoV-2 (COVID-19) pandemic has necessitated the development of novel hospital guidelines across a wide variety of specialties and clinical environments. Surgeons have been profoundly affected in many areas due to the widespread cessation of non-essential surgeries across the country. This has been particularly notable for orthopaedic surgeons, as elective surgeries compromise approximately $47 \%$ of orthopaedic care expenditures [1]. Many states have placed restrictions on elective procedures, but few have provided a definition of "elective," and only five states provided guidelines specific to orthopaedics [2]. Choosing which surgeries are classified as elective is not easily determined without some controversy and surgeons have been burdened with the challenge of identifying which operations to postpone [1-5]. The extent to which elective practices diminish is unknown, but a decline in volume is nearly certain. However, it remains unclear how our hospital, social, and government responses will affect trauma volumes and care.
It is reasonable to expect that injury pattern presentation will change for adults and children as there is less travel to work and school, increased time around the house, and limited access to public spaces. In pediatric orthopaedics, trauma is often the largest source of new referrals and a large portion of a surgeon's case volume [6-9]. With an average of $40 \%$ of pediatric injuries requiring hospitalization or emergency department care occurring in the home, we expected all aspects of the pediatric practice to increase as children spend more time around the house $[10,11]$. Due to a high quantity of

*Corresponding author: Daniel S Hayes, Geisinger Health System, 100 N Academy Ave, Danville, PA 17822, USA, Tel: 570939-9916

Accepted: November 24, 2020

Published online: November 26, 2020

Citation: Hayes DS, Holbert SE, Holbert JA, et al. (2020) Impact of COVID-19 on Pediatric and Adult Orthopaedics. J Orthop Surg Tech 3(2):221-227 
elective procedures in adult orthopaedics, we also expected the adult practice to decrease in all aspects except trauma, where we expected to see increased volume. Studies in general surgery and orthopaedics have shown adult and pediatric trauma to be positively correlated with temperature and negatively correlated with precipitation [12-15]. In pediatric orthopaedics, a higher incidence of trauma occurs during the school year when organized sports are active [15]. The purpose of this study is to report the effect of COVID-19 in pediatric and adult orthopaedic practices considering weather patterns, work and school activity, as well as social, government, and hospital guidelines.

\section{Methods}

This was a retrospective observation of orthopaedic clinic changes in response to COVID-19 across all Geisinger Health System locations. The study was approved by the IRB for exempt research status as per institutional policies. The study population comprised all orthopaedic patients identified by administrative data using orthopaedic department identifiers and operating room (OR) case reports. The number of outpatient (OP) visits, OP clinic procedures, and OR cases were collected from January 1 to May 26 for 2019 and 2020 for pediatrics and adults. The administrative OR case report was specific to one OR case encounter and did not count multiple procedures performed in the OR. Volume numbers were obtained from administrative databases and not clinically. Because of this, adult numbers were reported as a sum of all providers by specialty, while pediatric numbers could only be reported as a sum for all pediatric providers. Temperature and precipitation records were collected over the same periods using data obtained from the National Oceanic and Atmospheric Administration (NOAA) online climate data base. Weather data was acquired from the Williamsport, PA US site (ID City: US4200023), which aggregates data collected from 10 local weather stations. Changes in adult and pediatric orthopaedic practices are presented as a percent differ- ence change from 2019 to 2020 for each month reported. In instances when practice changes were greater than $100 \%$ from year to year, these were marked with an asterisk but capped at $100 \%$ when graphing to allow for all aspects to be displayed on the same plot.

\section{Results}

\section{Pediatrics}

All aspects of the pediatric practice decreased in March and April of 2020 compared to the previous year (Figure 1). Large decreases in OP visits and OR cases were observed in March and April compared to the previous two months (Figure 1). Pediatric OP visits decrease by $25.7 \%$ in March, $62.2 \%$ in April, and $57.5 \%$ in May and similar drops were present in OR cases for March (32.8\%) and April (76.1\%). There was an increase in OR cases in May 2020 (Figure 1). Outpatient procedures consistently were lower in 2020 than 2019, except in May, where procedures only decreased $3.7 \%$.

\section{Adults}

All aspects of the adult practice decreased in March, April, and May (Figure 1). Each aspect of the adult practice, OP visits, OP procedures, and OR cases, decreased in similar nature during this period (Figure 1). Outpatient visits decreased by 21.2\% in March, $64.5 \%$ in April, and $58.3 \%$ in May. Similar decreases were observed in OP Procedures (20.5\%, 67.4\%, $59.5 \%)$ and OR cases (19.8\%, 71.4\%, 47.5\%) for March, April, and May respectively. March, April, and May saw decreased OP visits for all specialties compared to the previous two months (Figure 2). Sports medicine saw the largest decrease in March compared to February, with OP visits dropping $75.8 \%$. The decrease in OP visits was unprecedented in all specialties except for hand and wound, where decreases were observed in the previous months (Figure 2). Trauma saw the largest decrease in any month, with a $76.5 \%$ decrease in May compared to the previous year. The month of April saw the

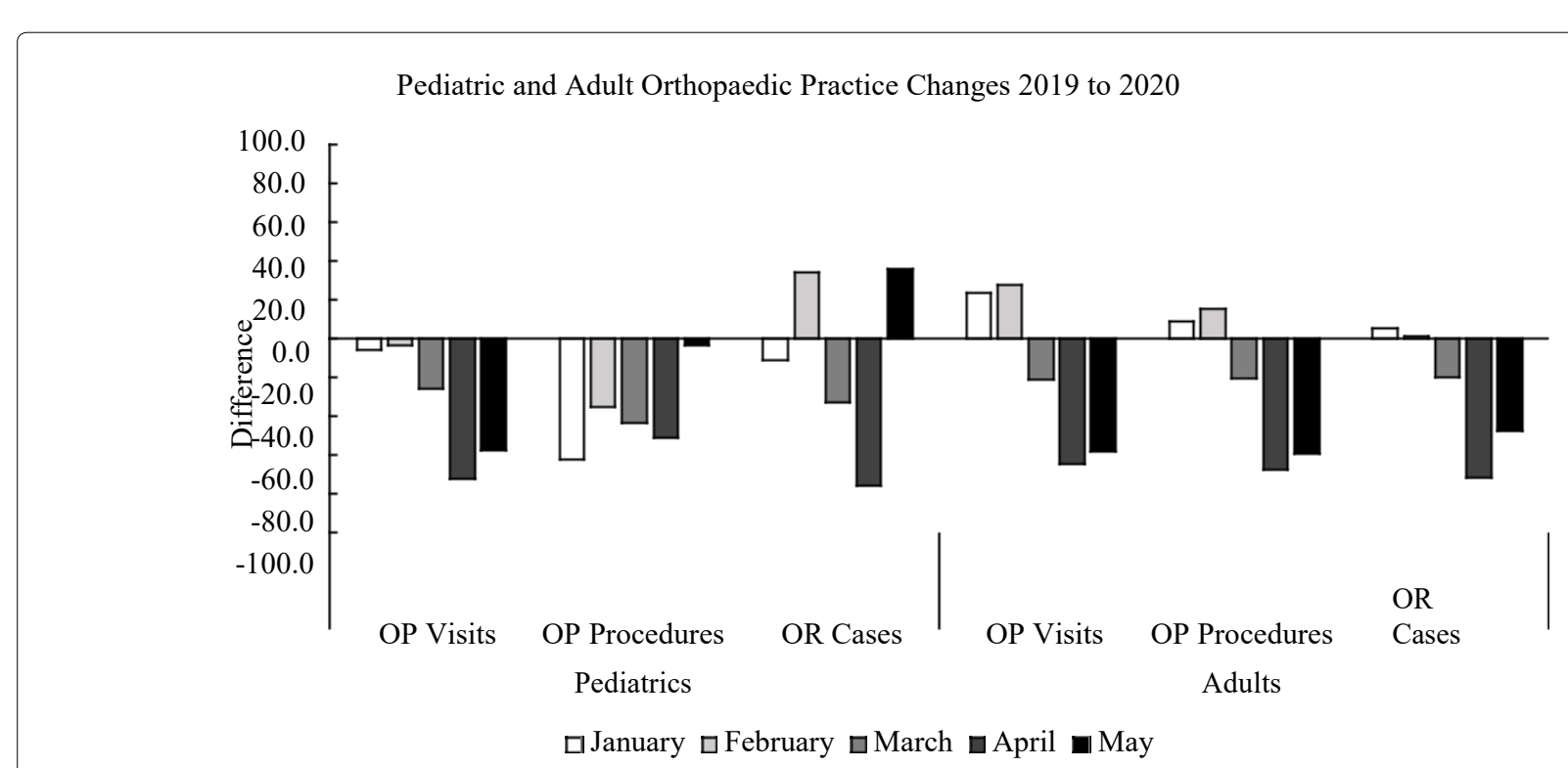

Figure 1: Changes in adult and pediatric practices from January through May of 2019 and 2020 shown by percent difference in number of OP visits, OP procedures, and OR cases for both groups. 


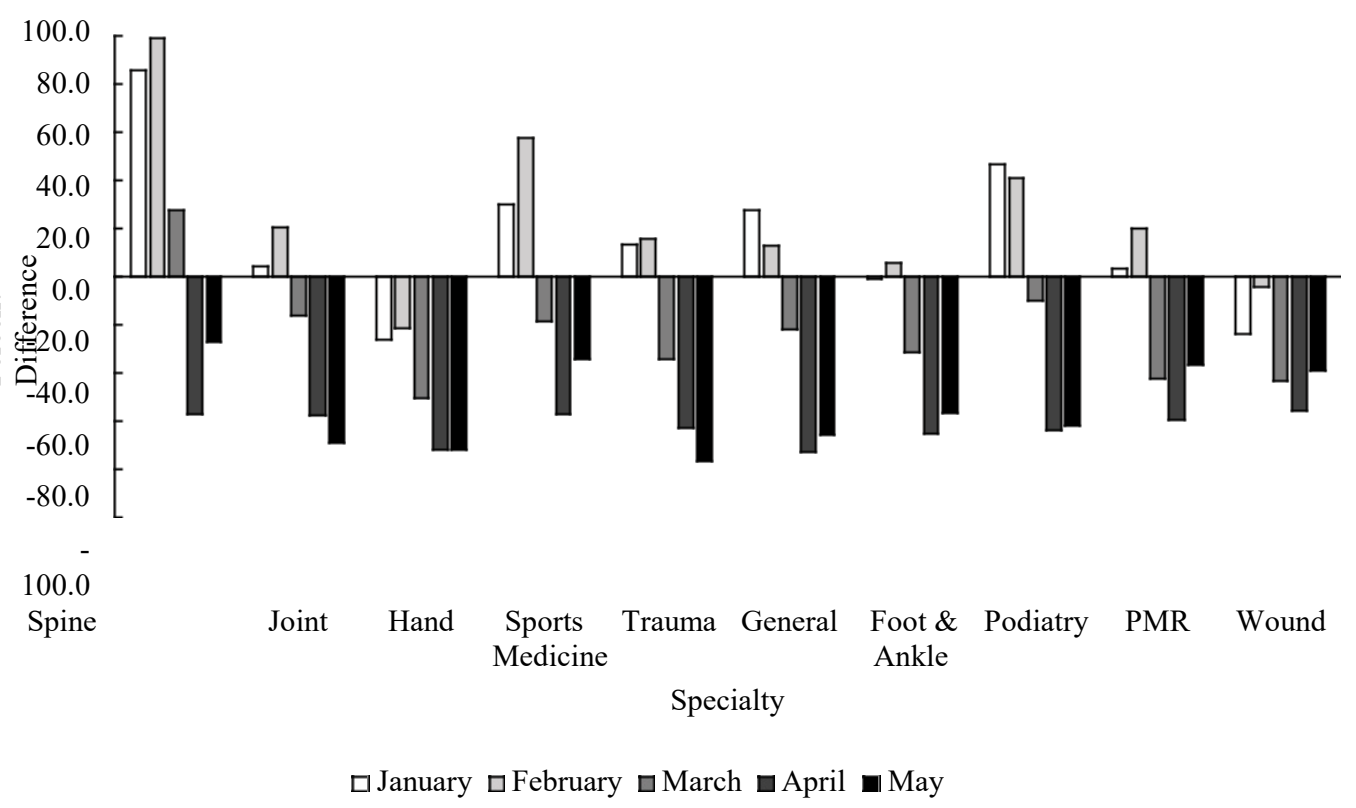

Figure 2: Changes in the number of adult orthopaedic OP visits from January through May of 2019 and 2020 across 10 specialties.

Adult Orthopaedic Outpatient Clinic Procedure Changes 2019 to 2020

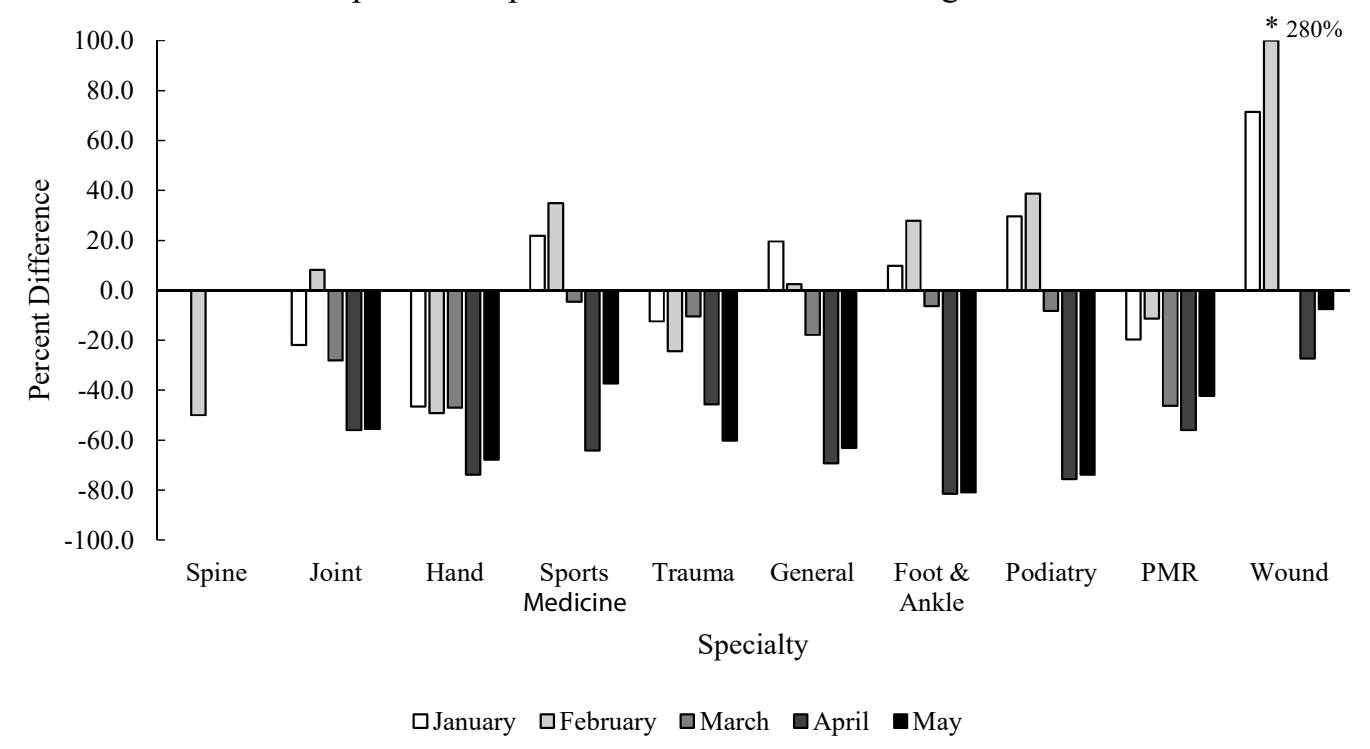

Figure 3: Changes in the number of adult orthopaedic OP clinic procedures from January through May of 2019 and 2020 across 10 specialties.

largest decrease in OP visits in nearly all specialties, except joints and trauma, where the largest decrease was in May (Figure 2). The number of OP clinic procedures performed greatly dropped in many specialties from February to March (Figure 3). Joint, sports medicine, foot $\&$ ankle, podiatry, and wound specialties suffered the largest decreases from February to March, with a continuing decrease compared to the previous year in April and May (Figure 3). The volume of OR cases dropped in all adult specialties, except podiatry, during March, April, and May of 2020 compared to the previous year (Figure 4). Trauma saw the smallest change from February to
March, with a $0.5 \%$ decrease in February and $1.1 \%$ decrease in March, although OR volume decreased greatly in the following months (Figure 4). The largest decrease in OR cases occurred in April and the second largest decrease in May for all specialties (Figure 4). No OR cases for wound or PMR specialties were performed during either year.

\section{Weather}

In both 2019 and 2020, the mean daily maximum temperature increased for every studied month (Figure 5). In 2020, the mean daily maximum temperature for every month was 


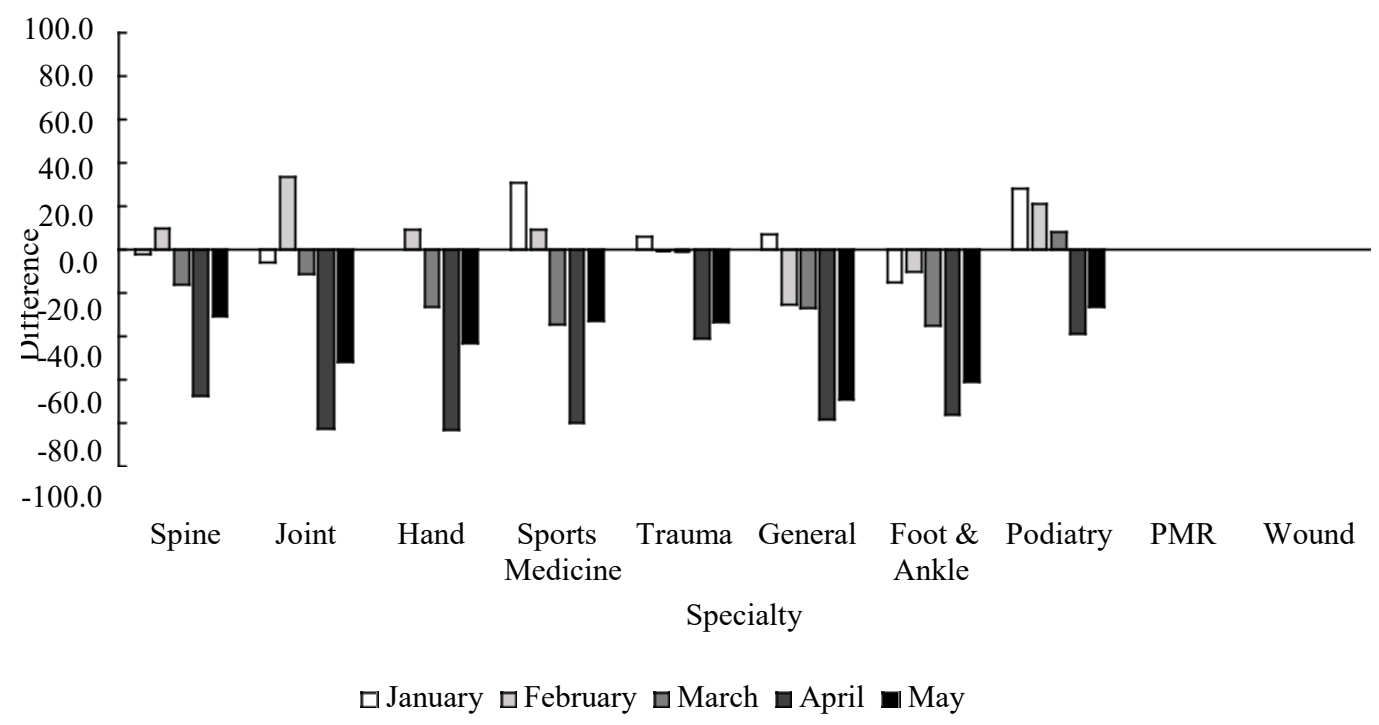

Figure 4: Changes in the number of adult orthopaedic OR cases from January through May of 2019 and 2020 across 10 specialties.

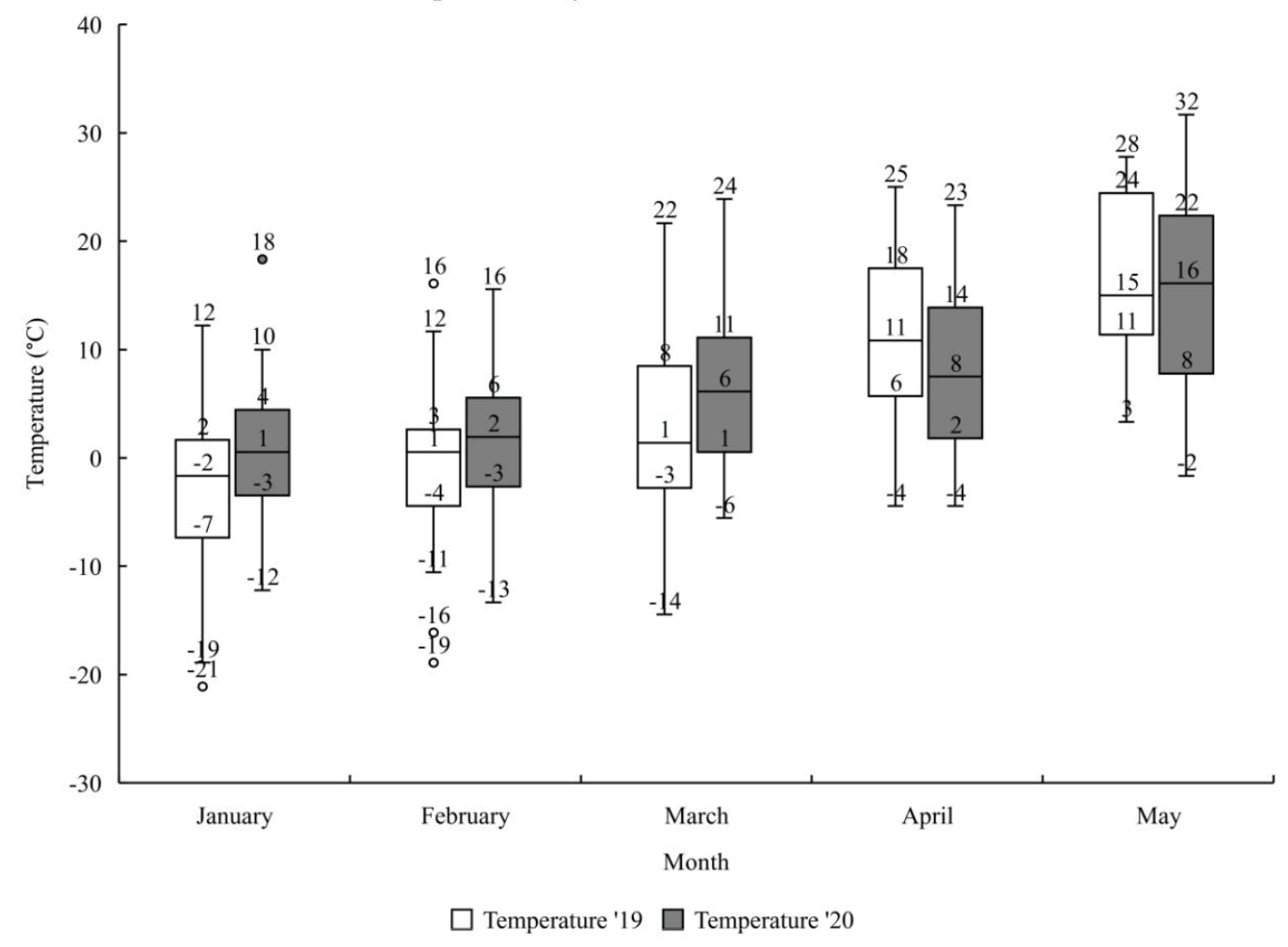

Figure 5: Daily maximum temperature recordings for the first five months of 2019 and 2020.

higher than 2019, except April (Figure 5). No obvious trends were observed in daily precipitation recordings between 2019 and 2020 (Figure 6). Cumulatively, 2019 was wetter in January (2019: 10.4; 2020: $6.1 \mathrm{~cm}^{3}$ ), February (2019: 8.1; 2020: 6.9 $\left.\mathrm{cm}^{3}\right)$, and May (2019: 14.5; 2020: $\left.8.6 \mathrm{~cm}^{3}\right)$. March and April of 2020 had more precipitation compared to 2019 (March 2019: 5.3; 2020: $7.9 \mathrm{~cm}^{3}$ and April 2019: 10.4; 2020: $15.2 \mathrm{~cm}^{3}$ ).

\section{Discussion}

The COVID-19 pandemic has confronted the orthopaedic community with challenges never faced by our profession. In comparison to the 2003 SARS outbreak, in Toronto, Canada, where the largest SARS outbreak occurred outside of Asia, one hospital reported $18 \%$ decreases in elective surgery and no changes of urgent surgery [16]. Recently, a 39-day study out of Glasgow, Scotland reported a $94 \%$ fall in elective or- 


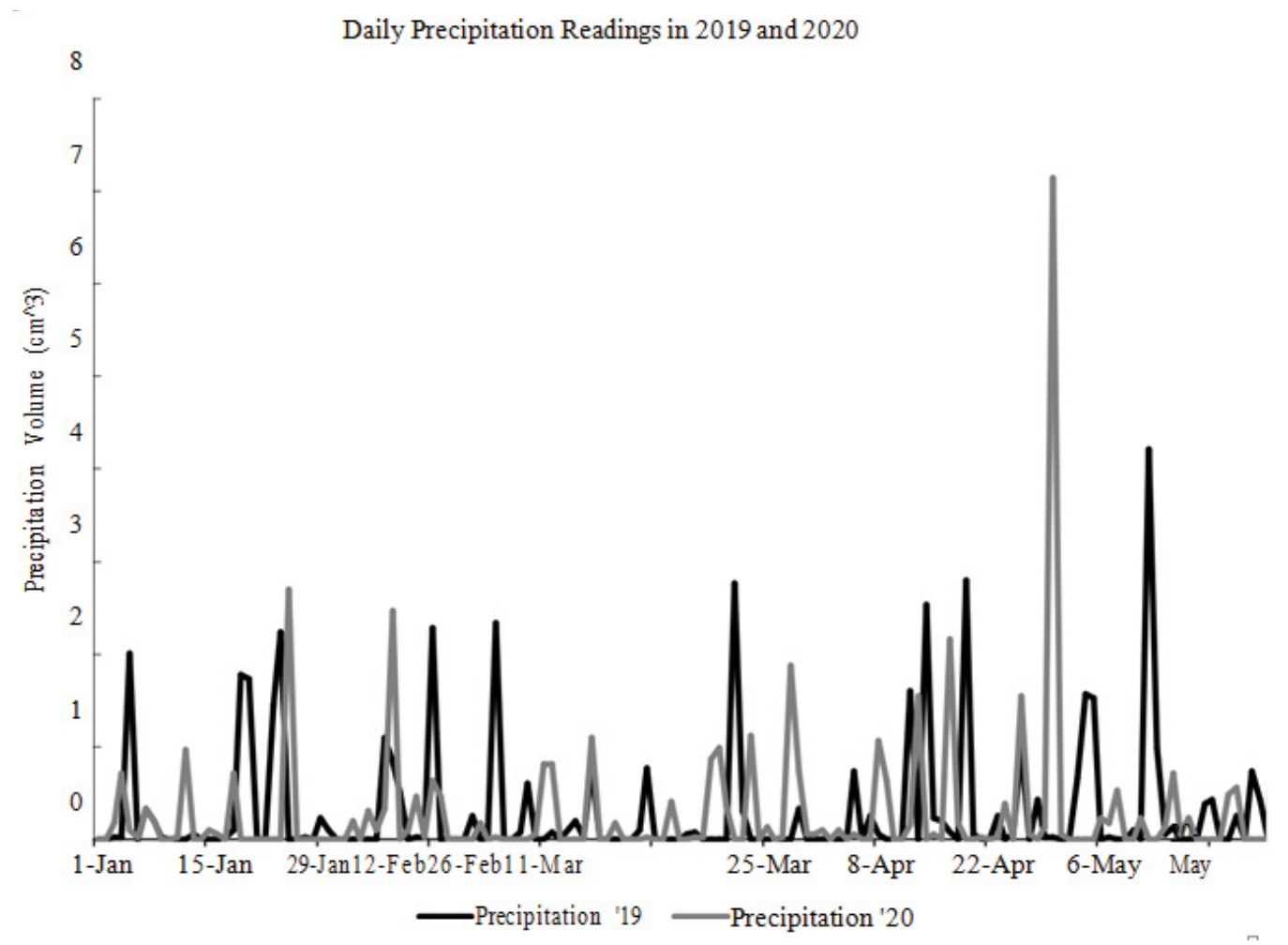

Figure 6: Daily precipitation volume for 2019 and 2020.

Table 1: Timeline of government, hospital, and social responses to COVID-19 related to the study.

\begin{tabular}{|l|l|}
\hline December 2019 & First report case Wuhan China: December 2019 [18]. \\
\hline January 20, 2020 & First case reported in US [19]. \\
\hline January 30, 2020 & WHO announced COVID as public health emergency of international concern [20]. \\
\hline March 5, 2020 & Geisinger restricts non-essential business travel. \\
\hline March 6, 2020 & First COVID case in Pennsylvania [21]. \\
\hline March 11, 2020 & COVID declared as pandemic by WHO (22]. \\
\hline March 13, 2020 & American College of Surgeons recommends postponing or canceling elective procedures [23]. \\
\hline March 13, 2020 & US declare state of emergency [24]. \\
\hline March 14, 2020 & US Surgeon General urges widespread cessation of elective surgery [25]. \\
\hline March 17, 2020 & Geisinger confirms first patients with presumed positive result for COVID [20]. \\
\hline March 18, 2020 & Pennsylvania Secretary of Health echoes calls to consider canceling elective surgeries [26]. \\
\hline March 18, 2020 & Geisinger MSKI places elective, non-urgent procedures on hold. \\
\hline April 1, 2020 & Tom Wolf issues Statewide Stay-at-Home order [27]. \\
\hline April 14, 2020 & Geisinger extends system wide elective procedures on hold through May 31, 2020. \\
\hline May 11, 2020 & Geisinger MSKI begins gradually reinstating elective procedures and outpatient visits. \\
\hline
\end{tabular}

thopaedic surgery and a $23 \%$ fall in trauma operations, but these numbers come from a 16-day lockdown period [17]. In the context of our study, the entire month of April was categorized by cessation of elective surgeries and a statewide stay-at-home order (Table 1) [18-27]. April saw the largest fall in operating procedures, with large decreases in departments with many elective surgeries (hand and joint $\geq 80.0 \%$ ), a $41.2 \%$ decrease in adult trauma, and $76.1 \%$ decrease in pediatric procedures. A particularly challenging decision-making process faced pediatric and adult trauma surgeons to contin- ue to provide the best practice while minimizing risk of infection.

In the early onset of the pandemic, there was an influx of clinical decision-making guidelines and recommendations, however there was disagreement and confusion in the literature and clinical judgement often remained the mainstay for correct decision making for each case [3-5,28-34]. The uniform consensus in the orthopaedic community was to reduce face-to-face follow-ups and utilize non-surgical management 
of injuries when possible [5,35]. These guidelines were followed at our institution, resulting in large drops in outpatient clinic visits and decreased surgical trauma cases. However, trauma surgery decreased in large part due to a widespread drop in patient presentation. Trauma is responsible for the majority of the surgical case load of our pediatric surgeons.

During the month of April all of our pediatric surgeons performed single digit case volumes for the entire month, resulting in the observed $76.1 \%$ decrease in OR cases compared to 2019. A large fall in pediatric trauma was also noted in March, despite the absence of stay-at-home orders. Adult trauma decreased during April, but remained steady in March, and we suspect this early decline in pediatric trauma to be related to a forward response to COVID concern by schools in the area. Local school districts were proactive in cancelling sports and after school activities, with many completely shutting down classes and activities for the school year as early as March 13, 2020 [36]. We believe the decreased opportunity for social activity contributed to the decrease in pediatric cases through limited organized sports play and access to play grounds both major sites of pediatric injury $[14,37,38]$. No obvious weather trends suggest poorer weather would have contributed to less activity, as there were no large temperature variations between 2019 and 2020 and 2019 was cumulatively a wetter year than 2020. Additionally, nonsurgical intervention in pediatrics may have been more attractive in some instances due to the high remodeling rate mitigating risks of residual deformity [39]. In the month of May, pediatrics saw an increase in surgical cases compared to the previous year. It is likely the increase was due to elective surgeries returning in May (Table 1) and pediatric surgeons beginning backlogged cases. However, it is also possible children became more active during this period despite social distancing guidelines.

As the societal response became more polarized, recent evidence suggest that the polarization is undermining compliance to social distancing, and likely contributing to increased social play among pediatrics [40-42]. It is also possible that this rise was a return to the normal elevated load shown in February. This trend is also mirrored in sports medicine procedures, where OR cases increased $331 \%(n=74)$ from February to May, but still resulted in a $32.9 \%$ decrease compared to 2019. Adult trauma cases remained decreased during May, suggesting that traumatic injury in adults remained low due to social distancing and lack of employment opportunity during this period. Future research should focus on injury pattern presented during this period and examine how treatment methodology affected outcome measurements. With an increase in removable casts and splints for upper extremity fractures, initial deformities are expected to increase.

We expect to see an increase in residual deformity in adults and a need for correctional operations in both pediatric and adult populations. The other adult specialties all suffered decreased OR cases, clinical visits, and clinical procedures during March, April, and May. Many procedures in these specialties were classified as elective or nonurgent and were placed on hold, resulting in decreased surgical volume during this period. Large scale surgical cancellation has never been seen on this scale before. There is little knowledge on the effects of delayed operative treatment in elective procedures and ramifications of these actions will need to be monitored closely $[43,44]$. Many procedures in these specialties are highly lucrative for the hospital system and the financial impact of decreasing surgical cases by $>70 \%$ in many cases is unknown. Our institution has taken action to increase surgical volumes following a return to elective procedures as a means of financial catch up.

This study is not without limitations. Use of administrative data prevents complete access to the clinical story, including areas of injury, injury severity, number of procedures performed, and reasoning for office visits. Administrative data was obtained using attending surgeons as identifiers and as such may not always align to the nature of the injury or age of the patient. This database does not record non-surgical procedures performed outside of the clinic, making it difficult to judge the volume of injuries that were treated nonoperatively. Telemedicine visits were not recorded as OP visits. While we do not believe this greatly impacted the visit numbers, it is possible the clinical load may have been stronger due to telemedicine visits. Once the COVID pandemic has settled, it will be important to reflect on the guidelines and changes to trauma and elective care management during this period. Research should focus on the negative consequences and positive lessons that can be learned.

\section{References}

1. (2019) Planned knee and hip replacement surgeries are on the rise in the USA. Blue Cross Blue Shield Association.

2. Sarac NJ, Sarac BA, Schoenbrunner AR, et al. (2020) A review of state guidelines for elective orthopaedic procedures during the COVID-19 outbreak. J Bone Joint Surg Am 102: 942-945.

3. Abolghasemian $\mathrm{M}$, Ebrahimzadeh $\mathrm{MH}$, Enayatollahi $\mathrm{MA}$, et al. (2020) Iranian orthopedics association (IOA) response guidance to COVID-19 pandemic. Arch Bone Jt Surgy 8: 209-217.

4. (2020) Statement from the ambulatory surgery center association regarding elective surgery and COVID-19. Ambulatory Surgery Center Association.

5. Vaccaro AR, Getz CL, Cohen BE, et al. (2020) Practice management during the COVID-19 pandemic. J Am Acad Orthop Surg 28: 464-470.

6. Chan DS, Podeszwa DA, Brown D, (2009) Expanding pediatric orthopaedic trauma volume at a pediatric level 1 trauma hospital. Journal Pediat Orthop 29: 612-617.

7. Hosseinzadeh P, DeVries CA, Nielsen E, et al. (2018) Changes in the practice of pediatric orthopaedic surgeons over the past decade: Analysis of the database of the american board of orthopaedic surgery. J Pediatr Orthop 38: 486-489.

8. Hosseinzadeh P, Obey MR, Nielsen E, et al. (2019) Orthopaedic care for children: Who provides it? How has it changed over the past decade? Analysis of the database of the american board of orthopaedic surgery. J Pediatr Orthop 39: e227-e231.

9. McCarthy JJ, Armstrong DG, Davey JP, et al. (2011) The current medical practice of the pediatric orthopaedic surgeon in north america. J Pediatr Orthop 31: 223-226.

10. (2020) Adjusting to a new pace of life during the COVID19 situation. BC Injury Research and Prevention Unit. 
11. Farrell S, Schaeffer EK, Mulpuri K (2020) Recommendations for the care of pediatric orthopedic patients during the COVID pandemic. J Am Acad Orthop Surg 28: e477-e486.

12. Bhattacharyya T, Millham FH (2001) Relationship between weather and seasonal factors and trauma admission volume at a level I trauma center. J Trauma Acute Care Surg 51: 118-122.

13. Friede KA, Osborne MC, Erickson DJ, et al. (2009) predicting trauma admissions: The effect of weather, weekday, and other variables. Minn Med 92: 47-49.

14. Livingston KS, Miller PE, Lierhaus A, et al. (2016) Does weather matter? The effect of weather patterns and temporal factors on pediatric orthopedic trauma volume. Open Orthop J 10: 550558.

15. Wilson JM, Staley CA, Boden AL, et al. (2018) The effect of season and weather on orthopaedic trauma: Consult volume is significantly correlated with daily weather. Adv Orthop 2018: 6057357.

16. Schull MJ, Stukel TA, Vermeulen MJ, et al. (2007) Effect of widespread restrictions on the use of hospital services during an outbreak of severe acute respiratory syndrome. CMAJ 176: 18271832.

17. Jenkins $P$ (2020) The early effect of COVID-19 on trauma and elective orthopaedic surgery. J Trauma Orthop.

18. Zhu N, Zhang D, Wang W, et al. (2020) A novel coronavirus from patients with pneumonia in china, 2019. N Engl J Med 382: 727 733.

19. Holshue ML, DeBolt C, Lindquist S, et al. (2020) First case of 2019 novel coronavirus in the united states. N Engl J Med 382: 929936.

20. (2020) Statement on the Second Meeting of the International Health Regulations (2005) Emergency Committee regarding the outbreak of novel coronavirus (2019-nCoV). World Health Organization.

21. (2020) COVID-19 data for Pennsylvania. Department of health.

22. Cucinotta D, Vanelli M (2020) WHO declares COVID-19 a Pandemic. Acta Biomed 91: 157-160.

23. (2020) COVID 19: Elective Case Triage Guidelines for Surgical Care. American College of Surgeons: COVID-19 and Surgery.

24. Trump D (2020) Proclamation on declaring a national emergency concerning the novel coronavirus disease (COVID-19) outbreak. White House Proclamations.

25. Luthi S (2020) Surgeon general advises hospitals to cancel elective surgeries. Politico.

26. DeJesus I (2020) Amid coronavirus spread, elective surgery should be canceled: Top Pa. health official. Penn Live Patriot News.

27. Mervosh S, Lu D, Swales Vsee (2020) Which states and cities have told residents to stay at home. The New York Times.

28. (2020) Maintaining trauma center access \& care during the COVID-19 Pandemic: Guidance document for trauma medical directors. American College of Surgeons: Committee on Trauma.

29. Forrester JD, Nassar AK, Maggio PM, et al. (2020) Precautions for operating room team members during the COVID-19 pandemic. J Am Coll Surg 230: 1098-1101.

30. Guy D, Bosco J, Savoie F (2020) AAOS guidelines for elective surgery during the COVID-19 pandemic. The American Academy of Orthopaedic Surgeons.

31. Khak M, Manafi Rasi A, Oryadi Zanjani L, et al. (2020) Trauma orthopedic surgeries in COVID-19 pandemic; A trauma management algorithm. Arch Bone Jt Surg 8: 286-290.

32. Massey PA, McClary K, Zhang AS, et al. (2020) Orthopaedic surgical selection and inpatient paradigms during the coronavirus (COVID-19) pandemic. J Am Acad Orthop Surg 28: 436-450.

33. Panjavi B, Kamrani RS, Ghane B (2020) The ups and downs of COVID-19 epidemics for orthopedic community. Arch Bone Jt Surg 8: 218-219.

34. Ross SW, Lauer CW, Miles WS, et al. (2020) Maximizing the calm before the storm: Tiered surgical response plan for novel coronavirus (COVID-19). J Am Coll Surg 230: 1080-1091.e3.

35. Loeb AE, Rao SS, Ficke JR, et al. (2020) departmental experience and lessons learned with accelerated introduction of telemedicine during the COVID-19 crisis. J Am Acad Orthop Surg 28: e469-e476.

36. (2020) School and local district event postponements and cancellations due to COVID-19. FOX56 Newsroom.

37. Bergeron N, Bergeron C, Lapointe L, et al. (2019) Don't take down the monkey bars: Rapid systematic review of playground-related injuries. Can Fam Physician 65: e121-e128.

38. Galano GJ, Vitale MA, Kessler MW, et al. (2005) The most frequent traumatic orthopaedic injuries from a national pediatric inpatient population. J Pediatr Orthop 25: 39-44.

39. Crawford SN, Lee LS, Izuka BH (2012) Closed Treatment of Overriding Distal Radial Fractures without Reduction in Children. J Bone Joint Surg Am 94: 246-252.

40. Cornelson K, Miloucheva B (2020) Political polarization, social fragmentation, and cooperation during a pandemic. Working Papers tecipa-663.

41. Garfin DR, Silver RC, Holman EA (2020) The novel coronavirus (COVID-2019) outbreak: Amplification of public health consequences by media exposure. Health Psychol 39: 355-357.

42. Merkley E, Bridgman A, Loewen PJ, et al. (2020) A Rare moment of cross-partisan consensus: elite and public response to the COVID-19 pandemic in canada. Can J Polit Sci 1-8.

43. Fedorak GT, DeRosa DC, Brough AK, et al. (2018) Increased time between diagnosis and surgery in slipped capital femoral epiphysis results in increased radiographic deformity. J Child Orthop 12: $232-235$.

44. Ifesanya AO, Ogundele OJ, Ifesanya JU (2013) Orthopaedic surgical treatment delays at a tertiary hospital in sub Saharan Africa: Communication gaps and implications for clinical outcomes. $\mathrm{Ni}-$ ger Med J 54: 420-425.

DOI: $10.36959 / 453 / 550$

Copyright: (C) 2020 Hayes DS, et al. This is an open-access article distributed under the terms of the Creative Commons Attribution License, which permits unrestricted use, distribution, and reproduction in any medium, provided the original author and source are credited. 